\title{
Cordyceps militaris induces tumor cell death via the caspase-dependent mitochondrial pathway in HepG2 and MCF-7 cells
}

\author{
JINGJING SONG $^{1}$, YINGWU WANG ${ }^{1}$, MEIYU TENG $^{1}$, SHIQIANG ZHANG ${ }^{1}$, MENGYA YIN $^{1}$, \\ JIAHUI LU ${ }^{1}$, YAN LIU ${ }^{1}$, ROBERT J LEE ${ }^{1,2}$, DI WANG ${ }^{1}$ and LESHENG TENG ${ }^{1}$ \\ ${ }^{1}$ School of Life Sciences, Jilin University, Changchun, Jilin 130012, P.R. China; ${ }^{2}$ Division of Pharmaceutics, \\ College of Pharmacy, The Ohio State University, Columbus, OH 43210, USA
}

Received May 18, 2015; Accepted March 30, 2016

DOI: $10.3892 / \mathrm{mmr} .2016 .5175$

\begin{abstract}
Cordyceps militaris (CM), an entomopathogenic fungus belonging to the class ascomycetes, possesses various pharmacological activities, including cytotoxic effects, on various types of human tumor cells. The present study investigated the anti-hepatocellular carcinoma (HCC) and anti-breast cancer effects of CM in in vitro and in vivo models. CM aqueous extract reduced cell viability, suppressed cell proliferation, inhibited cell migration ability, caused the over-release of lactate dehydrogenase, induced mitochondrial dysfunction and enhanced apoptotic rates in MCF-7 and HepG2 cells. The expression levels of cleaved poly (ADP ribose) polymerase and caspase-3, biomarkers of apoptosis, were increased following treatment with $\mathrm{CM}$ aqueous extract for $24 \mathrm{~h}$. Furthermore, in the MCF-7 and HepG2 cells, enhanced levels of B cell-associated $\mathrm{X}$ protein and cleaved caspase- 8 were observed in the CM-treated cells. Finally, the antitumor activities of CM in $\mathrm{HCC}$ and breast cancer were also confirmed in MCF-7- and HepG2-xengraft nude mice models. Collectively, the data obtained in the present study suggested that the cytotoxic effects of CM aqueous extract on HCC and breast cancer are associated with the caspase-dependent mitochondrial pathway.
\end{abstract}

\section{Introduction}

Breast cancer is reported to be the most common type of cancer diagnosed among women (1). Despite advances in medicine, the disease remains a substantial health problem worldwide. According to statistics, 1,500,000 cases of breast cancer were

Correspondence to: Dr Di Wang or Dr Lesheng Teng, School of Life Sciences, Jilin University, 2699 Qianjin Street, Changchun, Jilin 130012, P.R. China

E-mail: jluwangdi@outlook.com

E-mail: tenglesheng@jlu.edu.cn

Key words: Cordyceps militaris, hepatocellular carcinoma, breast cancer, apoptosis, mitochondrial, caspase diagnosed in 2010, representing almost one quarter of all the cases of cancer diagnosed in women (2). Primary liver cancer, particularly hepatocellular carcinoma (HCC), continues to be a growing global health problem, and has become the third most common cause of cancer-associated mortality worldwide, accounting for a mortality rate of $>800,000 /$ year $(2,3)$. The 5-year survival rate of HCC is $<10 \%$ (4). The results of standard chemotherapy and radiotherapy for the treatment of patients with breast cancer and HCC have remained unsatisfactory $(5,6)$. Despite efforts, no drugs have been manufactured for the satisfactory treatment of breast cancer and HCC in the past decade. Therefore, more effective alternative therapies or drugs with low side effect are required for the treatment of breast cancer and HCC.

Natural products have gradually became one of the most productive strategies in the development of antitumor agents (6), which possess potent cytotoxic abilities with fewer adverse effects. Neem leaf aqueous extract induces granulosa cell apoptosis via the mitochondria-caspase-mediated pathway (7). Parmotrema reticulatum, a tropical lichen, increases the B cell lymphoma-2 (Bcl-2)-associated X protein $(\mathrm{Bax}) / \mathrm{Bcl}-2$ ratio and activates the caspase family leading to apoptosis in MCF-7 cells (8). Cordyceps militaris (CM), an entomopathogenic fungus belonging to the class ascomycetes, is usually used as a traditional tonic in China and East Asia (9). A complex composition has been observed in the CM fruiting body, which is responsible for its various pharmacological activities (10). CM aqueous extract induces apoptotic MDA-MB-231 cell death via regulation of the phosphoinositide 3-kinase/AKT-associated mitochondrial pathway (11). CM inhibits B16-F10-xenograft tumor growth in C57BL/6 mice, associated with its angiogenic property (12). Due to activation of the caspase-associated pathway, $\mathrm{CM}$ aqueous extract also suppresses human premyelocytic leukemia cell growth (13). Although the cytotoxicity of CM towards MCF-7 and HepG2 cells has been reported $(14,15)$, the underlying mechanisms remain to be elucidated.

As an energy-dependent process, during apoptosis, living cells are involved in their own death in an organized manner, which is associated with various signaling pathways (16). Mitochondrial apoptosis, one of three death signaling 
pathways (17), is accompanied by mitochondrial depolarization, abnormal expression of members of the Bcl-2 family, the over-release of cytochrome $c$, and caspase-3 activation $(18,19)$. Caspase-3 is generally considered to be an important effector protease during apoptosis (18), the proteolytic maturation of which is catalyzed by initiator caspases (caspase- $8,-9$ and -10) (20). The auto-catalytic activation of procasapase- 8 in extrinsic apoptosis leads to the decrease of mitochondrial membrane permeability $(\Delta \psi \mathrm{m})(21,22)$.

The purpose of the present study was to investigate the in vitro and in vivo pro-apoptotic effects of $\mathrm{CM}$ on $\mathrm{HCC}$ and breast cancer. The results revealed that $\mathrm{CM}$ induced MCF-7 and HepG2 cell apoptosis, predominantly through the caspase-dependent mitochondrial pathway. The results of the present study indicated the potential for the addition of $\mathrm{CM}$ to the list of possible agents for the treatment of HCC and breast cancer.

\section{Materials and methods}

CM extract preparation. Extraction of the CM fruiting body (purchased from Qianxiang Co., Ltd., Shenyang, China) was performed at $45^{\circ} \mathrm{C}$ for $3 \mathrm{~h}$, followed by extraction at $80^{\circ} \mathrm{C}$ for another $3.5 \mathrm{~h}$ in double distilled water (D.D. water). The merging supernatant was concentrated in an R1002B evaporator (Shanghai Shensheng Technology Co., Ltd., Shanghai, China) under reduced pressure $(<10 \mathrm{kPa})$, and was further freeze-dried to produce a solid aqueous extract. Analysis of the data revealed that the CM fruiting body water extract contained $29.04 \%$ polysaccharides, $20.45 \%$ total proteins, $6.01 \%$ cordycepic acid, $0.204 \%$ adenosine and $0.347 \%$ cordycepin. The polysaccharides were measured via phenolsulfuric acid method (23), the total proteins were analysed via Kjeldahl method (24), and the cordycepic acid, adenosine and cordycepin were analysed via high performance liquid chromatography (25).

Cell culture. HepG2 cells (human HCC line; HB-8065) and MCF-7 cells (human breast carcinoma cell line; HTB-22) were cultured in Dulbecco's modified Eagle's medium (DMEM) supplemented with $10 \%$ fetal bovine serum, $100 \mathrm{U} / \mathrm{ml}$ penicillin and $100 \mu \mathrm{g} / \mathrm{ml}$ streptomycin (all obtained from Gibco; Thermo Fisher Scientific, Inc., Waltham, MA, USA) under a humidified atmosphere containing $5 \% / 95 \% \mathrm{CO}_{2} /$ air at $37^{\circ} \mathrm{C}$. The cultured medium was refreshed every 3 days. The cells were ready for treatment when the confluence of cells in the plates reached. All reagents used for cell culture were obtained from Invitrogen; Thermo Fisher Scientific, Inc.

Cell viability analysis. The cell viability was measured using a 3-(4,5)-dimethylthiahiazo(-z-y1)-3,5-di-pheny-tetrazoliumromide (MTT; Sigma-Aldrich, St. Louis, MO, USA) assay (26). The MCF-7 and HepG2 cells were seeded into 96-well plates at a density of 5,000 per well for $24 \mathrm{~h}$. Following treatment with $\mathrm{CM}$ at doses of $0.1,0.2,0.4,1.0$ and $2.0 \mathrm{mg} / \mathrm{ml}$ for $24 \mathrm{~h}$, the cells were incubated with $0.5 \mathrm{mg} / \mathrm{ml} \mathrm{MTT} \mathrm{for} 4 \mathrm{~h}$ at $37^{\circ} \mathrm{C}$ in the dark. Purple formazan crystals were solubilized by adding $100 \mu \mathrm{l}$ dimethyl sulfoxide, and the absorbance was measured using an iMark microplate reader at a wavelength of $490 \mathrm{~nm}$ (Bio-Rad Laboratories, Inc., Hercules, CA, USA).
Lactate dehydrogenase $(\mathrm{LDH})$ release analysis. The MCF-7 and HepG2 cells were seeded into 24-well plates at a density of $5 \times 10^{4}$ per well. Following treatment with $\mathrm{CM}$ at doses of $0.1,0.2,0.4,1.0$ and $2.0 \mathrm{mg} / \mathrm{ml}$ for $24 \mathrm{~h}$, the cultured medium was collected and centrifuged at $1,000 \mathrm{x} \mathrm{g}$ for $5 \mathrm{~min}$ at $4^{\circ} \mathrm{C}$. The LDH released into the culture medium was measured using an LDH assay kit (cat. no. 20141205; Nanjing Jiancheng Bioengineering Institute, Nanjing, China).

Colony formation assays. Crystal violet staining was performed to examine the colony formation. Briefly, the MCF-7 and HepG2 cells were seeded into 6-well plates at a density of $5 \times 10^{4}$ cells/well. The cells were treated with CM at $0.1,0.2,0.4,1.0$ and $2.0 \mathrm{mg} / \mathrm{ml}$ for 7 days. The medium was replaced, either with DMEM only or the CM in complete DMEM, every 2 days. Following treatment, the cells were fixed in $75 \%$ methanol for $10 \mathrm{~min}$ at $4^{\circ} \mathrm{C}$ and stained with $0.1 \%$ crystal violet (Sigma-Aldrich) for $30 \mathrm{~min}$. Images were subsequently captured.

Apoptosis analysis via Hoechst staining. The MCF-7 and HepG2 cells were seeded into 6-well plates at a density of $2 \times 10^{5}$ cells/well. The cells were treated with CM at $0.5,1.0$ and $2.0 \mathrm{mg} / \mathrm{ml}$ for $24 \mathrm{~h}$. The treated cells were then incubated with Hoechst $33342(5 \mu \mathrm{g} / \mathrm{ml}$; BD Biosciences, San Jose, CA, USA) for $30 \mathrm{~min}$ at $37^{\circ} \mathrm{C}$ in the dark. Following three washes with phosphate-buffered saline (PBS), images of the altered fluorescent color in the mitochondria were captured using a fluorescent microscope (magnification, x20; chargecoupled device camera; TE2000; Nikon Corporation, Tokyo, Japan). The percentage of apoptotic cells was analyzed by measuring the fluorescence intensity using Image $\mathbf{J}$ software (rsb.info.nih.gov/ij/download.html) and expressed as the ratio of red to green fluorescence intensity.

Migration assay. The cells were plated in 6-well plates ( $4 \times 10^{4}$ cells/well) and cultured to $>90 \%$ confluence, following which the cell layer was scraped with a p200 pipette tip (Shanghai Jingke Scientific Instrument Co., Ltd., Shanghai, China). The cells were treated with CM at $0.5,1.0$ and $2.0 \mathrm{mg} / \mathrm{ml}$ for $24 \mathrm{~h}$, following which the distances of the migrating cells were used to evaluate the migratory ability of the cells. The width of the wound was expressed as a percentage of the control group.

Assessment of $\Delta \psi m$. To determine the alterations in $\Delta \psi \mathrm{m}$ in the cells, 5,5',6,6'-Tetrachloro-1,1',3,3'-tetraethylbenzimidazolylcarbocyanine iodide (JC-1; Sigma-Aldrich), which selectively enters mitochondria, was used. The MCF-7 and HepG2 cells were seeded into 6 -well plates at a density of $2 \times 10^{5}$ cells/well. The cells were treated with CM at doses of $0.5,1.0$ and $2.0 \mathrm{mg} / \mathrm{ml}$ for $12 \mathrm{~h}$. The treated cells were then incubated with $2 \mu \mathrm{M} \mathrm{JC}-1$ at $37^{\circ} \mathrm{C}$ for $20 \mathrm{~min}$ in the dark. Following three washes with PBS, alterations in the fluorescent color in the mitochondria were analyzed using fluorescent microscopy (magnification, x20; charge-coupled device camera; TE2000; Nikon Corporation). Red fluorescence indicated healthy cells with a high $\Delta \psi \mathrm{m}$, whereas green fluorescence indicated apoptotic or unhealthy cells with a low $\Delta \psi \mathrm{m}$. 
MCF-7- and HepG2-xenograft tumor models. The present study was approved by the ethics committee of Changchun University (Changchun, China). Male 6-week-old BALB/c athymic nude mice, purchased from Weitonglihua Laboratory Animal Technology Co., Ltd. (Beijing China; SCXK 2012-0001), were used for the in vivo experiments in the present study. The experimental animal protocol was approved by the Animal Ethics Committee of Jilin University (Changchun, China). The mice were housed in groups of two in clear plastic cages, and were maintained on a $12 \mathrm{~h}$ light/dark cycle at $23 \pm 1^{\circ} \mathrm{C}$ with water and food available ad libitum.

The tumors were generated by harvesting MCF-7 and HepG2 cells from mid-log phase cultures. A volume of $0.1 \mathrm{ml}\left(1 \times 10^{8}\right.$ cells $\left./ \mathrm{ml}\right)$ of MCF-7 or HepG 2 cell suspension was subcutaneously injected into the right side of the waist of each mouse. After 4 days, when the largest diameter of the tumors measured 2-3 $\mathrm{mm}$, the mice were randomly divided into two groups ( $\mathrm{n}=3$ each). The mice were administered with $1 \mathrm{~g} / \mathrm{kg} \mathrm{CM}$ (treated group) or D.D. water (vehicle group) orally every other day continuously for 2 weeks. The tumor dimensions and body weights were measured every other day. Tumor volume $\left(\mathrm{mm}^{3}\right)$ was estimated using the following equation: Tumor volume $\left(\mathrm{mm}^{3}\right)=$ Length $\mathrm{x}(\text { width })^{2} \times 0.5$. At the end of the experiment, the mice were sacrificed by administration of $200 \mathrm{mg} / \mathrm{kg}$ pentobarbital (Sigma-Aldrich). The tumor tissues were carefully dissected from each mouse and stored at $-130^{\circ} \mathrm{C}$ prior to western blot analysis.

Western blot analysis. The cells were plated into 6-well plates at a density of $2 \times 10^{5}$ cells per well. The following day, the cells were treated with CM $(0.5,1.0$ and $2.0 \mathrm{mg} / \mathrm{ml})$ for $24 \mathrm{~h}$. The cells or tumor tissues were lysed using radioimmunoprecipitation assay buffer (Sigma-Aldrich) containing 1\% protease inhibitor cocktail (Sigma-Aldrich) and 2\% phenylmethanesulfonyl fluoride (Sigma-Aldrich).Tumor tissues were homogenized using a ZW-A trace vibrator (Ronghua Instrument Manufacturing Co., Ltd.). Lysates were centrifuged at $10,000 \mathrm{x}$ g for 5 mins at $4^{\circ} \mathrm{C}$ and the concentration of protein was determined by the Coomassie brilliant blue method (Nanjing Jiancheng Biotechnology Co., Ltd., Nanjing, China) The proteins $(30 \mu \mathrm{g})$ were separated on a 12\% SDS-PAGE gel [materials obtained from Sinopharm Chemical Reagent Co., Ltd. (Shanghai, China)] and transferred electrophoretically onto nitrocellulose membranes $(0.45 \mu \mathrm{m}$; Bio Basic, Inc., Markham, ON, Canada). The transferred membranes were then blocked with $5 \%$ bovine serum albumin (Sigma-Aldrich) for $4 \mathrm{~h}$ at $4^{\circ} \mathrm{C}$ prior to blotting with the following primary antibodies at $4^{\circ} \mathrm{C}$ overnight, at a dilution of $1: 1,000$ : Monoclonal rabbit anti-cleaved poly (ADP-ribose) polymerase (PARP; cat. no. ab32064; Abcam, Cambridge, UK), polyclonal rabbit anti-cleaved caspase-3 (cat. no. ab13847; Abcam), polyclonal rabbit anti-cleaved caspase-8 (cat. no. ab25901; Abcam), monoclonal rabbit anti-Bax (cat. no. ab32503; Abcam) and polyclonal rabbit anti-glyceraldehyde-3-phosphate dehydrogenase (cat. no. ABS16; EMD Millipore, Billerica, MA,USA). The membranes were subsequently incubated with horseradish peroxidase-conjugated mouse anti-rabbit secondary antibody (cat. no. sc-2357; Santa Cruz Biotechnology, Inc., Dallas, TX, USA). Chemiluminescence was analyzed using Amersham ECL Western Blotting Detection reagent (cat. no. RPN2106; GE Healthcare, Buckinghamshire, UK). The intensities of the bands were quantified by scanning densitometry using Image $\mathbf{J}$ software.

Statistical analysis. All data are expressed as the mean \pm standard deviation and were analyzed using one-way analysis of variance, followed by post-hoc multiple comparison (Dunn's test). SPSS software version 16.0 (SPSS, Inc. Chicago, IL, USA). $\mathrm{P}<0.05$ was considered to indicate a statistically significant difference.

\section{Results}

CM exhibits cytotoxic effects in MCF-7 and HepG2 cells. Dose- and time-dependent reductions in cell viability were observed in the MCF-7 and HepG2 cells following incubation with CM. The 24-h half maximal inhibitory concentrations of $\mathrm{CM}$ in the MCF-7 and HepG2 cells were 1.096 and $0.791 \mathrm{mg} / \mathrm{ml}$, respectively $(\mathrm{P}<0.01$; Fig. $1 \mathrm{~A}$ and B). Following exposure to $\mathrm{CM}$ at doses between 0.2 and $2.0 \mathrm{mg} / \mathrm{ml}$ for $24 \mathrm{~h}$, 8.45-16.80\% increases in LDH release were observed in the MCF-7 cells $(\mathrm{P}<0.05$; Fig. $1 \mathrm{C})$. Similarly, treatment with $\mathrm{CM}$ for $24 \mathrm{~h}(0.2-2.0 \mathrm{mg} / \mathrm{ml})$ enhanced $\mathrm{LDH}$ release in the HepG2 cells by 4.6-7.0\% ( $\mathrm{P}<0.05$; Fig. 1D). The effects of $\mathrm{CM}$ on the abilities of the MCF-7 and HepG2 cells to form colonies were monitored for 7 days, the marked inhibitory effect of CM on MCF-7 cell colony formation was apparent at $0.2 \mathrm{mg} / \mathrm{ml}$, and the clonogenic ability of the MCF-7 cells was completely inhibited following treatment with $2.0 \mathrm{mg} / \mathrm{ml} \mathrm{CM}$ (Fig. 1E). In addition, 0.4-2.0 mg/ml CM exerted significant inhibitory effects on HepG2 cell colony formation (Fig. 1F). Hoechst 33342 staining corroborated that CM at doses between 0.5 and $2.0 \mathrm{mg} / \mathrm{ml}$ markedly induced nuclear apoptosis in the MCF-7 and HepG2 cells, indicated by the enhanced intensity of blue fluorescence (Fig. 2A). Additionally, a wound healing assay was performed to observe the inhibitory effect of $\mathrm{CM}$ on the migratory abilities of the MCF-7 and HepG2 cell. Following incubation for $24 \mathrm{~h}$, the wound areas in the untreated cells were almost healed. By contrast, the migratory abilities of the MCF-7 and HepG2 cells were significantly inhibited following CM treatment at specific doses (Fig. 2B). Collectively, these data confirmed the cytotoxic properties of $\mathrm{CM}$ in MCF-7 and HepG2 cells.

CM causes alterations in apoptosis, mitochondrial function and the expression levels of pro-apoptotic proteins. Mitochondrial function is one of the factors responsible for cell apoptosis. JC-1 staining was applied in the present study to analyze the alterations of $\Delta \psi \mathrm{m}$. Incubation with $\mathrm{CM}$ for $24 \mathrm{~h} C M$ caused significant losses of $\Delta \psi \mathrm{m}$ in the MCF-7 and HepG2 cells, evidenced by enhanced green fluorescence intensity (Fig. 3A).

As one of the factors involved in the Bcl-2 family, Bax contributes to cell apoptosis and mitochondrial function (27). Treatment with $\mathrm{CM}$ at doses between 0.5 and $2.0 \mathrm{mg} / \mathrm{ml}$ markedly enhanced the expression levels of Bax in the MCF-7 and HepG2 cells (Fig. 3B). The activation of caspase-3 and PARP is considered as to be a hallmark of apoptosis, and this was enhanced following incubation with $\mathrm{CM}$ for $24 \mathrm{~h}$ in the present study (Fig. 3B). In addition, increases in the activation of caspase- 8 were observed in the CM-treated MCF-7 and HepG2 cells (Fig. 3B). Collectively, CM induced intracellular 
A

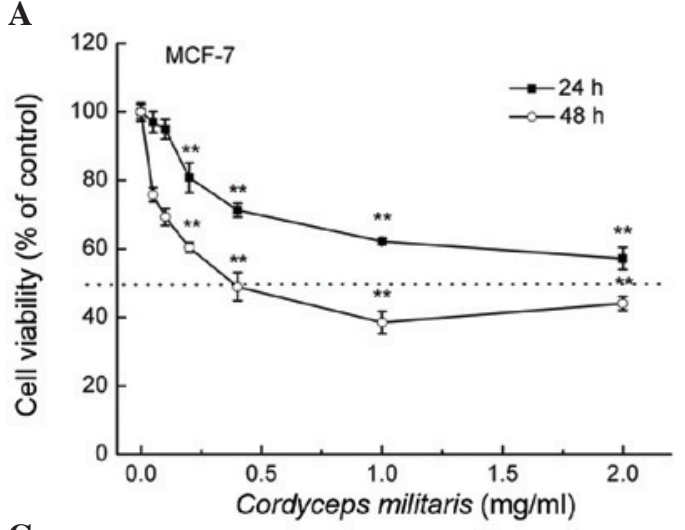

C
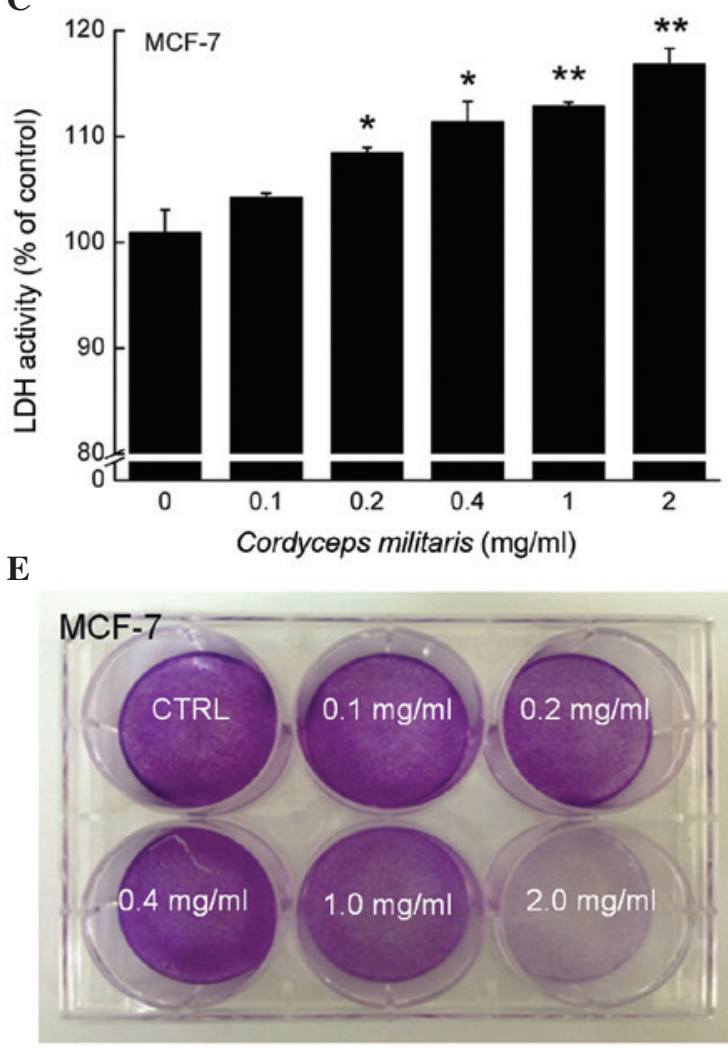

B

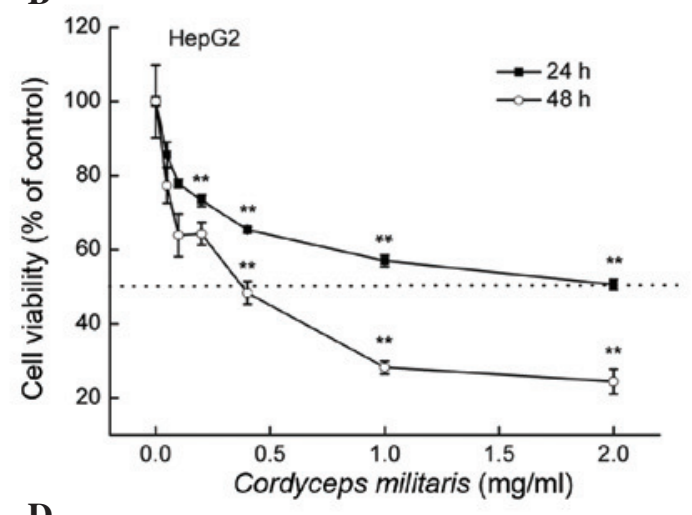

D

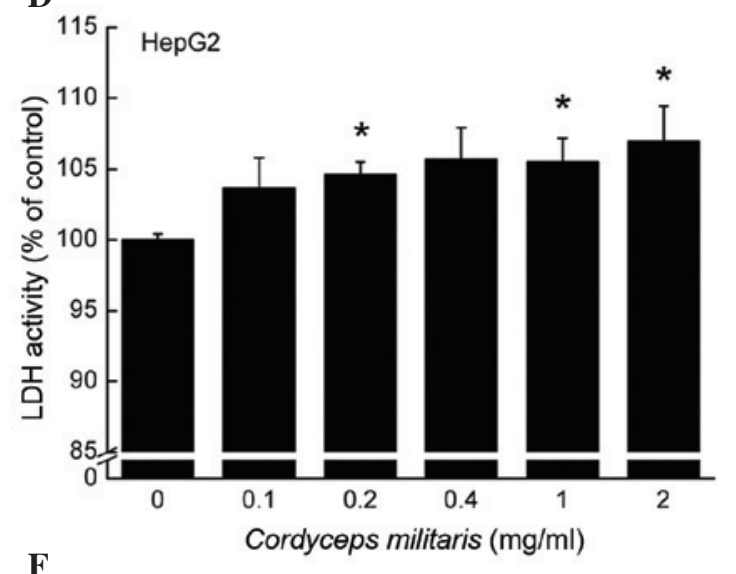

F

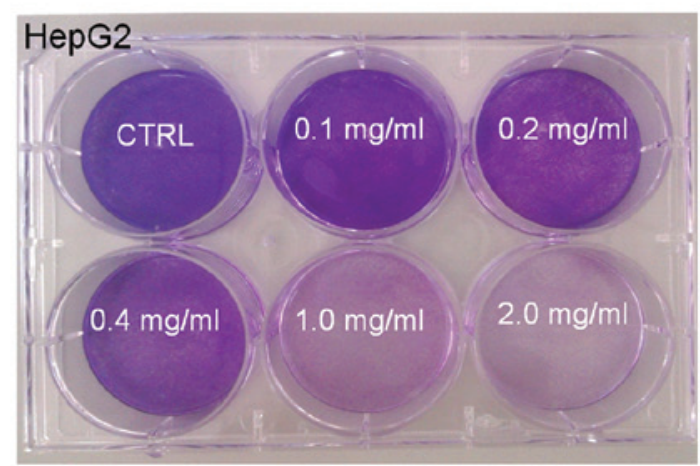

Figure 1. CM induces cell damage in MCF-7 and HepG2 cells. Dose- and time-dependent suppression in cell viability was observed following treatment with CM for 24 and $48 \mathrm{~h}$ in (A) MCF-7 and (B) HepG2 cells. Exposure to CM for $24 \mathrm{~h}$ caused over-release of LDH in (C) MCF-7 and (D) HepG2 cells. Data are expressed as the mean \pm standard deviation $(\mathrm{n}=6)$ and were analyzed using one-way analysis of variance. ${ }^{*} \mathrm{P}<0.05$ and ${ }^{* *} \mathrm{P}<0.01$, vs. untreated cells. Treatment with CM for 7 days inhibited (E) MCF-7 and (F) HepG2 cell proliferation, detected using crystal violet staining. CM, Cordyceps militaris; LDH, lactate dehydrogenase; CTRL, control.

toxicity, which was associated with its regulation of mitochondrial function and the expression of pro-apoptotic proteins.

CM inhibits MCF-7- and HepG2- xenograft tumor growth in nude mice. In the MCF-7- and HepG2-xenograft tumor nude mice models, tumor growth inhibition was most marked in the mice treated with $1 \mathrm{~g} / \mathrm{kg} \mathrm{CM}$ for 2 weeks (every other day), where tumor sizes reduced by almost $188.2 \%$, compared with the vehicle-treated mice in the MCF-7 cells $(\mathrm{P}<0.05$; Figs. 4A and B). Similar to the results obtained from the in vitro experiment, the administration of CM for 14 days enhanced the expression levels of cleaved PARP, cleaved caspase-3, cleaved caspase-8 and Bax in the MCF-7- and HepG2-xenograft tumor tissues, compared with the vehicle-treated mice $(\mathrm{P}<0.05$; Fig. 4C). Similar results were observed in the HepG2 cells, with tumor growth inhibited by almost $82.7 \%$, compared with the vehicle-treated mice (Fig. 5A and B), and administration of CM for 14 days enhancing the expression levels of cleaved PARP, cleaved caspase-3, cleaved caspase- 8 and $\mathrm{Bax}(\mathrm{P}<0.05$; Fig. 5C). These in vivo data provided further evidence of $\mathrm{CM}$-mediated antitumor activities in $\mathrm{HCC}$ and breast cancer.

\section{Discussion}

The inhibitory activities of CM on MCF-7 and HepG2 cell growth have been reported in previous studies (28-31); however, their associated mechanisms remain to be elucidated. The present study investigated the potential antitumor effects of CM on MCF-7 and HepG2 cells, and examined the possible underlying mechanisms. Compared with other 
A
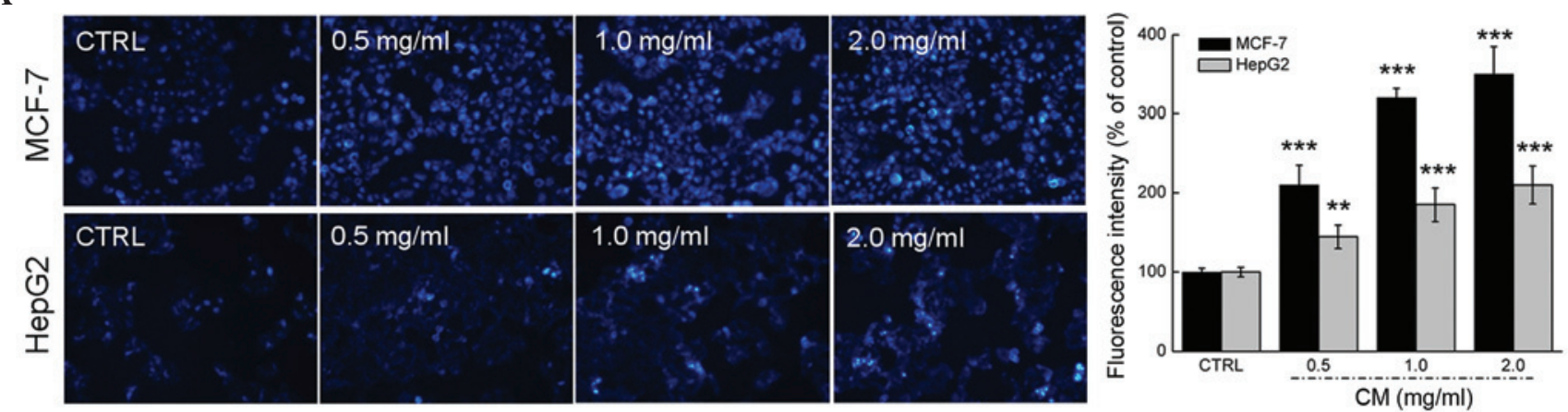

B
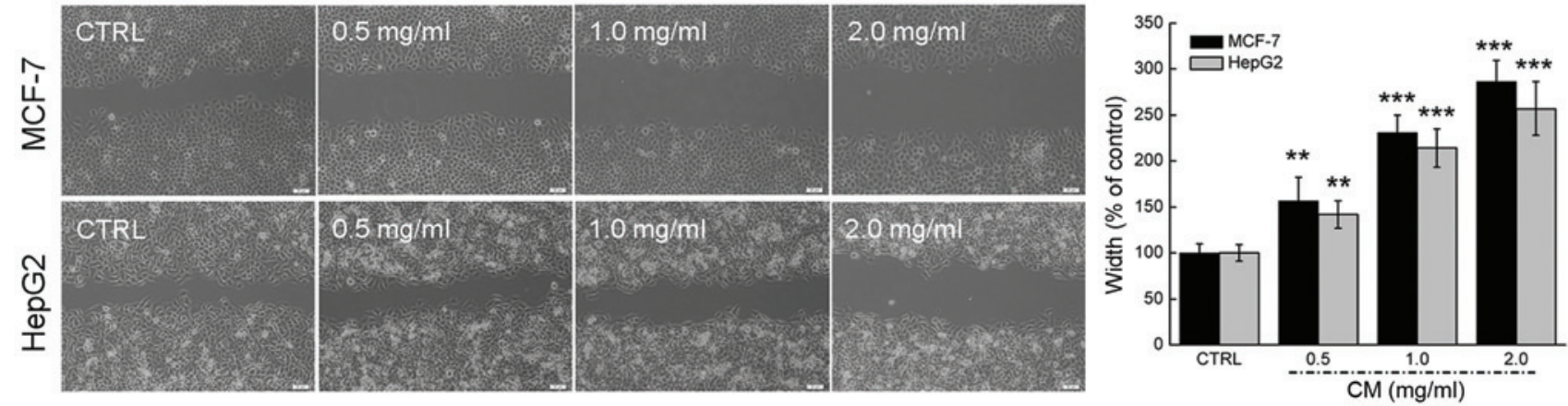

Figure 2. CM increases apoptosis and inhibits migration in MCF-7 and HepG2 cells. (A) CM significantly enhanced the apoptotic rates of the MCF-7 and HepG2 cells. Apoptosis (nuclear morphology) was examined using Hoechst 33342 staining (magnification, x20). The percentage of apoptotic cells was analyzed by measuring fluorescence intensity via Image J software. (B) CM treatment inhibited the migration ability of the MCF-7 and HepG2 cells, determined using a wound-healing assay (magnification, $\mathrm{x} 10)$. Data are expressed as mean \pm standard deviation $(\mathrm{n}=3) .{ }^{* *} \mathrm{P}<0.01$ and ${ }^{* * *} \mathrm{P}<0.001 \mathrm{vs}$. control group. CM, Cordyceps militaris; CTRL, control.

A
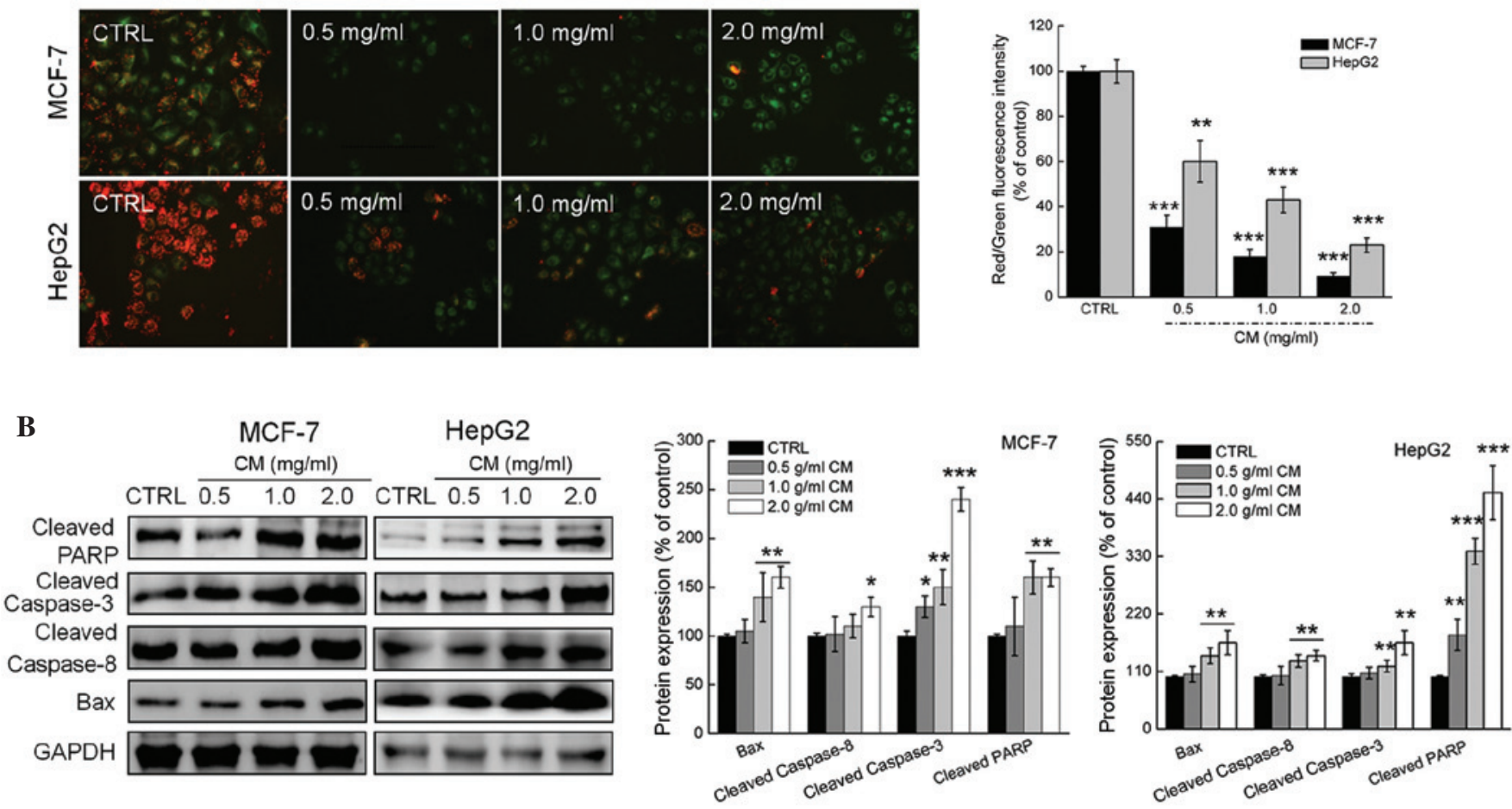

Figure 3. Effects of $\mathrm{CM}$ on mitochondrial dysfunction and the expressions of pro-apoptotic proteins in MCF-7 and HepG2 cells. (A) Dissipation of $\Delta \psi \mathrm{m}$ was observed in cells exposed to $0.5-2.0 \mathrm{mg} / \mathrm{ml} \mathrm{CM}$ for $12 \mathrm{~h}$ and quantified as the ratio of red to green fluorescence intensity. (B) CM treatment resulted in an increases in the expression levels of cleaved PARP, cleaved caspase- 3 and cleaved caspase- 8 . The protein expression levels were quantified by densitometry analysis and normalized to the corresponding GAPDH levels. Data are expressed as the mean \pm standard deviation $(n=3) .{ }^{*} \mathrm{P}<0.05,{ }^{* *} \mathrm{P}<0.01,{ }^{* * * *} \mathrm{P}<0.001$ vs. control. All experiments were repeated three times. CM, Cordyceps militaris; $\Delta \psi \mathrm{m}$, mitochondrial membrane potential; CTRL, control; PARP, Bax, B cell lymphoma-2-associated X protein; GAPDH, glyceraldehyde-3-phosphate dehydrogenase. 
A

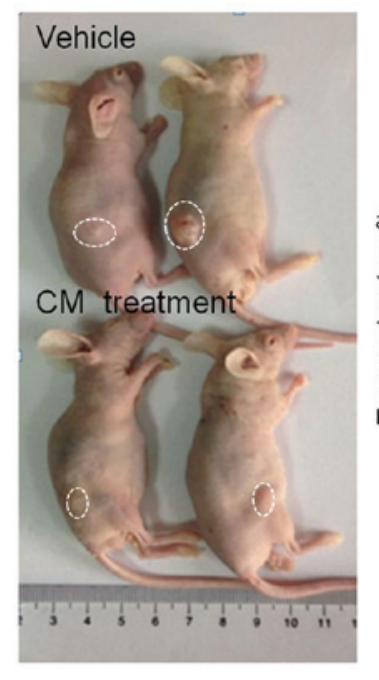

B

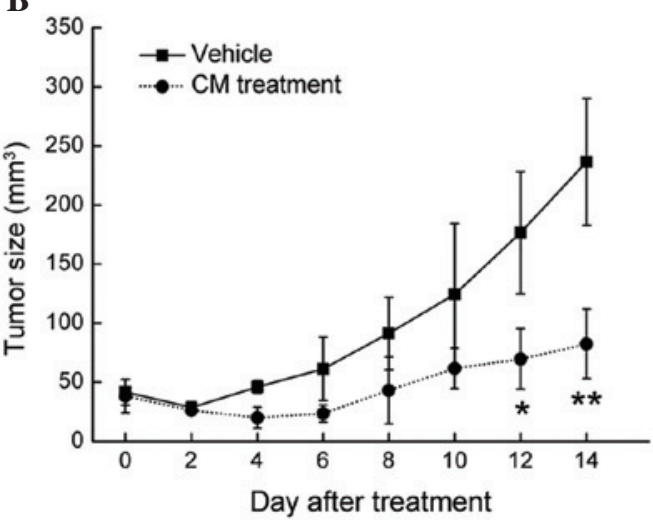

D

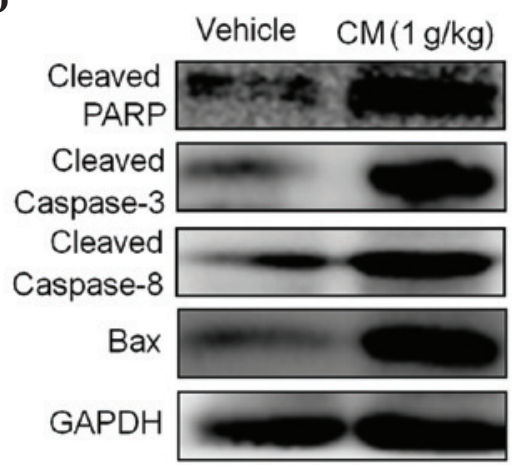

C
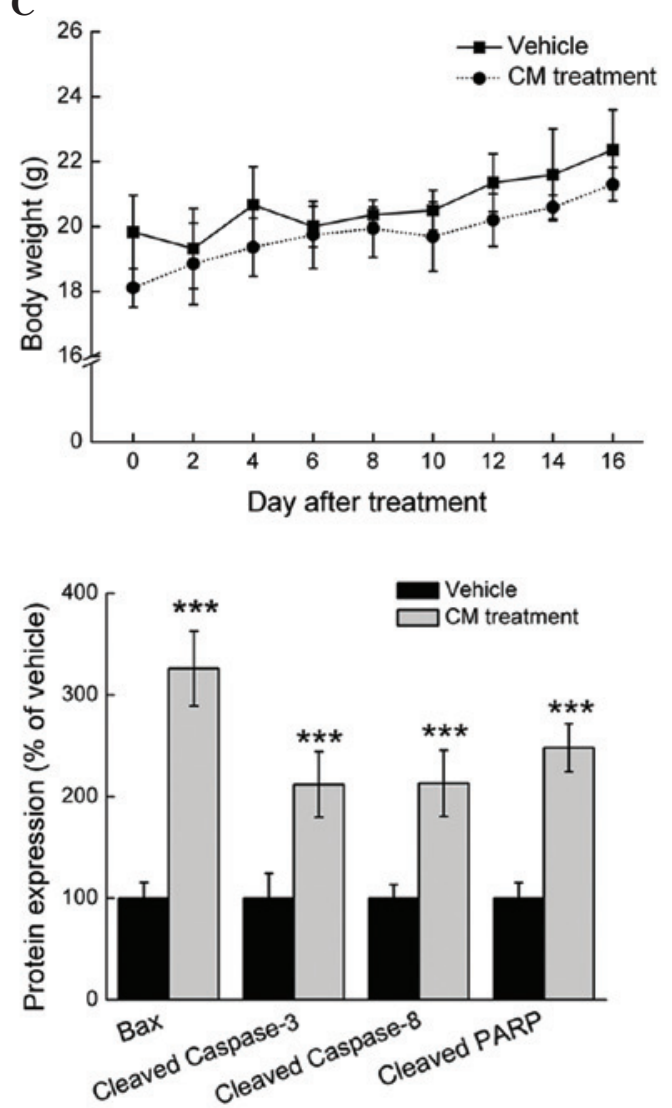

Figure 4. CM has a suppressive effect in the MCF-7-xenograft nude mice model. Male BALB/c athymic nude mice bearing MCF-7 tumors were treated with phosphate-buffered saline (vehicle) or CM $(1 \mathrm{~g} / \mathrm{kg})$ via intraperitoneal administration every other day for 14 days. (A) Examples of tumor growth in the animals. (B) Growth curves of MCF-7-xenograft tumors in the CM-and vehicle-treated nude mice. Tumor sizes were measured every 2 days. $\mathrm{n}=4$, analyzed using one-way analysis of variance. ${ }^{*} \mathrm{P}<0.05$ and ${ }^{* *} \mathrm{P}<0.01$ vs. vehicle. (C) Body weight of MCF-7-xenografted nude mice. (D) Levels of pro-apoptotic proteins in tumor tissues, detected via western blot analysis. Protein expression levels were quantified by densitometry analysis and normalized to GAPDH. Data are expressed as the mean \pm standard deviation. ${ }^{* * *} \mathrm{P}<0.001$ vs. vehicle. CM, Cordyceps militaris; CTRL, control; PARP, poly (ADP ribose) polymerase; Bax, B cell lymphoma-2-associated X protein; GAPDH, glyceraldehyde-3-phosphate dehydrogenase.

reported bioactive extracts $(32,33)$, the crude drug nature of CM suggests it may have multi-effective components, which may target various molecules. Due to the systemic targeting, less adverse side effects are expected. CM has been used for thousands of years as a crude drug and a traditional medicine in East Asia, further emphasizing its safety and minimal side effects.

Apoptosis is a physiological suicide mechanism, which occurs during normal tissue turnover. Mitochondria, triggered by diverse apoptotic stimuli, commonly exist as the predominant functional organelle for anticancer drugs $(34,35)$. Mitochondria control the intrinsic pathway of apoptosis, in which $\Delta \psi \mathrm{m}$ induces the activation of caspases and other catabolic enzymes $(36,37)$. The functional loss of mitochondria is accompanied with the dissipation of $\Delta \psi \mathrm{m}$ (38), which was confirmed in the present study. As reported previously, caspase- 8 is located predominantly in the mitochondria, and active caspase- 8 forms a complex with the $\mathrm{BH} 3$-interacting domain death agonist protein on the mitochondria, which leads to decreased $\Delta \psi \mathrm{m}$ (39-41). During this process, caspase- 8 undergoes dimerization and cleaves itself to become fully activated (39). Large quantities of active caspase- 8 can lead to the direct cleavage of effector caspase in the cytosol (42). Bcl-2 family members, which are located in the outer mitochondrial membrane, are essential mediators in the regulation of $\Delta \psi \mathrm{m}$ (27). Bax, a pro-apoptotic protein of the Bcl-2 family, acts as an important regulatory factor in mitochondria-mediated apoptosis (27). It has been reported that reactivation of the Bax gene induces mitochondrial apoptosis in cholangiocarcinoma cells (43). Collectively, the data obtained in the present study confirmed that the mitochondrial apoptotic pathway was involved in CM-meditated antitumor effects.

In addition, a reduction of $\Delta \psi \mathrm{m}$ promotes the release of cytochrome $c$ from the mitochondria (44), which leads to the activation of caspase- 3 and other apoptosis-inducing molecules (45). Caspase- 3 is central in the induction of the apoptotic program (46), and is important for cell death in a tissue-, cell type- or death stimulus-specific manner (46). As reported, caspase- 3 is essential for the characteristic changes in cell morphology and certain biochemical events associated with the execution and completion of apoptosis (46-48). Of note, caspase-3-defective embryonic stem cells exhibit marked resistance to apoptosis induced by ultraviolet irradiation 
A
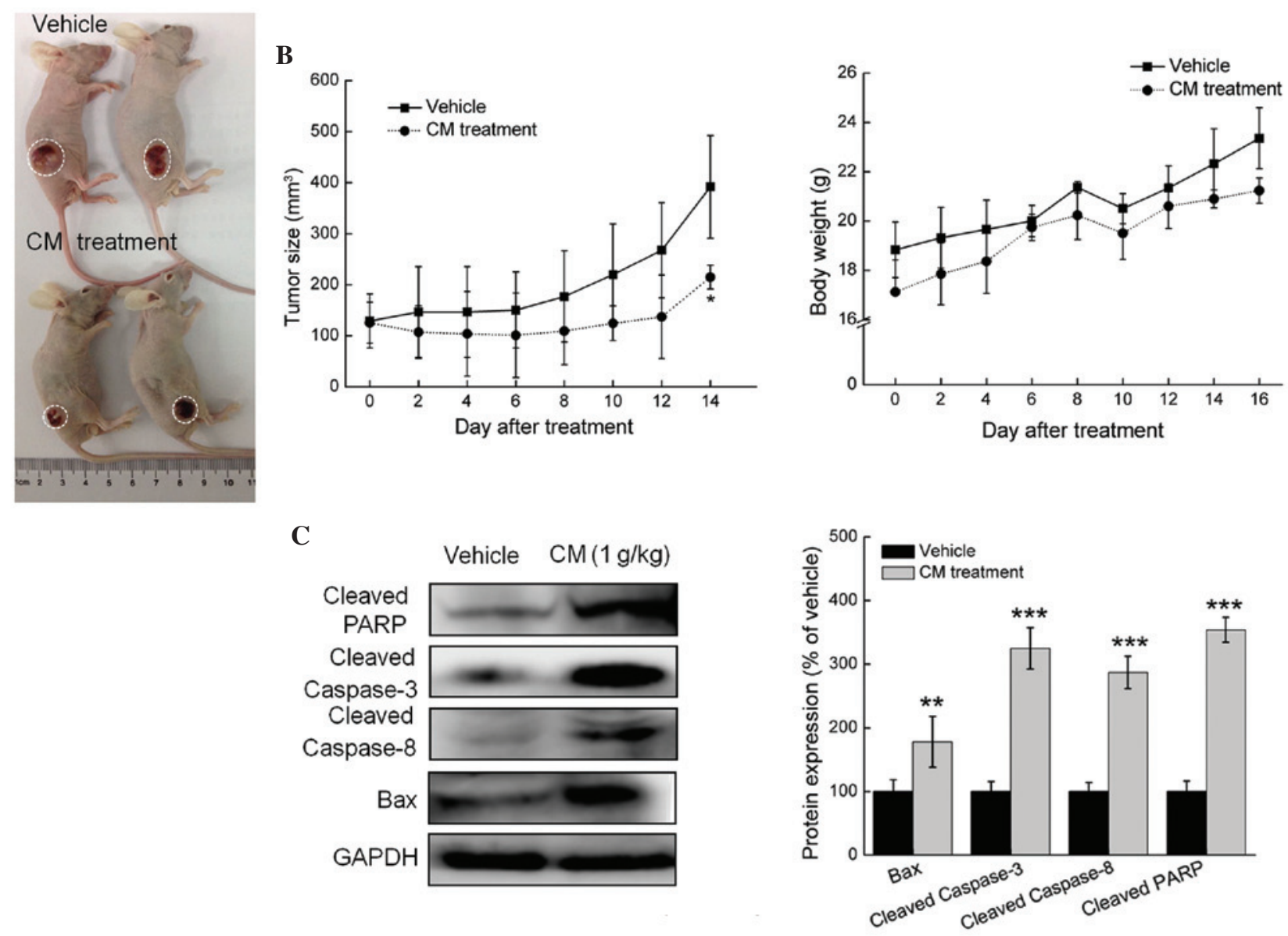

Figure 5. CM has a suppressive effect in the HepG2-xenograft nude mice model. (A) Examples of tumor growth between CM- and vehicle-treated male BALB/c athymic nude mice bearing HepG2 tumors. (B) Growth curves of HepG2-xenograft tumors in CM- and vehicle-treated nude mice. Tumor sizes were measured every 2 days. Data are expressed as the mean \pm standard deviation $(\mathrm{n}=4)$ and were analyzed using one-way analysis of variance. ${ }^{*} \mathrm{P}<0.05$, vs. vehicle group. (C) Activation of PARP, caspase-3 and caspase-8, and the levels of Bax in tumor tissues were detected using Western blot analysis. The average fold changes in band intensity, compared with the vehicle group, were marked. ${ }^{* *} \mathrm{P}<0.01$ and ${ }^{* * * *} \mathrm{P}<0.001$ vs. control. CM, Cordyceps militaris; CTRL, control; PARP, poly (ADP ribose) polymerase; Bax, B cell lymphoma-2-associated X protein; GAPDH, glyceraldehyde-3-phosphate dehydrogenase.

and osmotic shock (49). In the present study, the activation of caspase-3 was observed, and the enhanced expression of PARP was also found. PARP is considered to be one of the most important downstream substrates of caspase-3 (50). The activity of PARP is completely dependent on the number of DNA breaks, and it is totally inactive in the absence of DNA breaks (51-53). The over-activation of PARP triggers a cell death cascade, which results in tissue damage (52). It has been reported that z-DEVD-fmk can significantly inhibit apoptosis mediated by the caspase-3/PARP apoptotic signaling pathway (50). Together, CM-mediated MCF-7 and HepG2 cell apoptosis is associated with the caspase-dependent mitochondrial pathway.

In conclusion, the present study confirmed the anti-HCC and anti-breast cancer effects of $\mathrm{CM}$ aqueous extract in in vitro and in vivo experiments. CM leads to the over-release of LDH, dissipation of $\Delta \psi \mathrm{m}$ and abnormal expression of pro-apoptotic proteins. The caspase-dependent mitochondrial pathway contributed to CM-induced cytotoxicity in the MCF-7 and HepG2 cells. These findings provide pharmacological evidence that $\mathrm{CM}$ possesses antitumor effects in $\mathrm{HCC}$ and breast cancer, offering potential as a chemotherapeutic agent.

\section{Acknowledgements}

This study was supported by the Science and Technology Key Project of Jilin Province in China (grant no. 20130201006ZY), the Natural Science foundation of P.R. China (grant no. 81402955) and the 'Twelfth Five-Year' Science and Technology Planning Project of Jilin Province in China (grant no. 2014B033).

\section{References}

1. Hosseini BA, Pasdaran A, Kazemi T, Shanehbandi D, Karami H, Orangi M and Baradaran B: Dichloromethane fractions of Scrophularia oxysepala extract induce apoptosis in MCF-7 human breast cancer cells. Bosn J Basic Med Sci 15: 26-32, 2015.

2. Jemal A, Bray F, Center MM, Ferlay J, Ward E and Forman D: Global Cancer Statistics. CA Cancer J Clin 61: 69-90, 2011.

3. Forner A and Bruix J: Hepatocellular carcinoma-Authors' reply. Lancet 380: 470-471, 2012.

4. Johnson PJ: Hepatocellular carcinoma: Is current therapy really altering outcome? Gut 51: 459-462, 2002.

5. Arii S, Yamaoka Y, Futagawa S, Inoue K, Kobayashi K, Kojiro M, Makuuchi M, Nakamura Y, Okita K and Yamada R: Results of surgical and nonsurgical treatment for small-sized hepatocellular carcinomas: A retrospective and nationwide survey in Japan. The liver cancer study group of Japan. Hepatology 32: 1224-1229, 2000 . 
6. Chang $\mathrm{CH}$, Chen SJ and Liu CY: Adjuvant treatments of breast cancer increase the risk of depressive disorders: A population-based study. J Affect Disord 182: 44-49, 2015.

7. Chaube SK, Shrivastav TG, Tiwari M, Prasad S, Tripathi A and Pandey AK: Neem (Azadirachta indica L) leaf extract deteriorates oocyte quality by inducing ROS-mediated apoptosis in mammals. Springerplus 3: 464, 2014.

8. Ghate NB, Chaudhuri D, Sarkar R, Sajem AL, Panja S, Rout J and Mandal N: An antioxidant extract of tropical lichen, Parmotrema reticulatum, induces cell cycle arrest and apoptosis in breast carcinoma cell line MCF-7. PLoS One 8: e82293, 2013.

9. Das SK, Masuda M, Sakurai A and Sakakibara M: Medicinal uses of the mushroom Cordyceps militaris: Current state and prospects. Fitoterapia 81: 961-968, 2010.

10. Ng TB and Wang HX: Pharmacological actions of Cordyceps, a prized folk medicine. J Pharm Pharmacol 57: 1509-1519, 2005.

11. Jin CY, Kim GY and Choi YH: Induction of apoptosis by aqueous extract of Cordyceps militaris through activation of caspases and inactivation of Akt in human breast cancer MDA-MB-231 cells. J Microbiol Biotechnol 18: 1997-2003, 2008.

12. Yoo HS, Shin JW, Cho JH, Son CG, Lee YW, Park SY and Cho CK: Effects of Cordyceps militaris extract on angiogenesis and tumor growth. Acta Pharmacol Sin 25: 657-665, 2004.

13. Lee H, Kim YJ, Kim HW, Lee DH, Sung MK and Park T: Induction of apoptosis by Cordyceps militaris through activation of caspase-3 in leukemia HL-60 cells. Biol Pharm Bull 29: 670-674, 2006.

14. Reis FS, Barros L, Calhelha RC, Cirić A, van Griensven LJ, Soković M, Ferreira IC: The methanolic extract of Cordyceps militaris (L.) Link fruiting body shows antioxidant, antibacterial, antifungal and antihuman tumor cell lines properties. Food Chem Toxicol 62: 91-98, 2013

15. Jing Y, Cui X, Chen Z, Huang L, Song L, Liu T, Lv W and Yu R: Elucidation and biological activities of a new polysaccharide from cultured Cordyceps militaris. Carbohydr Polym 102: 288-296, 2014.

16. Nakagawa S, Shiraishi T, Kihara S and Tabuchi K: Detection of DNA strand breaks associated with apoptosis in human brain tumors. Virchows Arch 427: 175-179, 1995.

17. Pintus F, Floris G and Rufini A: Nutrient availability links mitochondria, apoptosis and obesity. Aging (Albany NY) 4: 734-741, 2012.

18. Chen R, Liu S, Piao F, Wang Z, Qi Y, Li S, Zhang D and Shen J: 2,5 -Hexanedione induced apoptosis in mesenchymal stem cells from rat bone marrow via mitochondria-dependent caspase-3 pathway. Ind Health 53: 222-235, 2015.

19. Wang Y, Wu Y, Luo K, Liu Y, Zhou M, Yan S, Shi H and Cai Y: The protective effects of selenium on cadmium-induced oxidative stress and apoptosis via mitochondria pathway in mice kidney. Food Chem Toxicol 58: 61-67, 2013.

20. Hu Q, Wu D, Chen W, Yan Z and Shi Y: Proteolytic processing of the caspase-9 zymogen is required for apoptosome-mediated activation of caspase-9. J Biol Chem 288: 15142-15147, 2013.

21. Boatright KM, Renatus M, Scott FL, Sperandio S, Shin H, Pedersen IM, Ricci JE, Edris WA, Sutherlin DP, Green DR and Salvesen GS: A unified model for apical caspase activation. Mol Cell 11: 529-541, 2003.

22. Kroemer G, Dallaporta B and Resche-Rigon M: The mitochondrial death/life regulator in apoptosis and necrosis. Annu Rev Physiol 60: 619-642, 1998

23. Baharara J and Amini E: The potential of brittle star extracted polysaccharide in promoting apoptosis via intrinsic signaling pathway. Avicenna J Med Biotechnol 7: 151-158, 2015.

24. Kato M, Yamazaki T, Kato H, Eyama S, Goto M, Yoshioka M and Takatsu A: Development of high-purity certified reference materials for 17 proteinogenic amino acids by traceable titration methods. Anal Sci 31: 805-814, 2015.

25. Li SP, Yang FQ and Tsim KW: Quality control of Cordyceps sinensis, a valued traditional Chinese medicine. J Pharm Biomed Anal 41: 1571-1584, 2006.

26. Mosmann T: Rapid colorimetric assay for cellular growth and survival: Application to proliferation and cytotoxicity assays. J Immunol Methods 65: 55-63, 1983.

27. Chan SL and Yu VC: Proteins of the bcl-2 family in apoptosis signalling: From mechanistic insights to therapeutic opportunities. Clin Exp Pharmacol Physiol 31: 119-128, 2004.
28. Reis FS, Barros L, Calhelha RC, Cirić A, van Griensven LJ, Soković $M$ and Ferreira IC: The methanolic extract of Cordyceps militaris (L.) Link fruiting body shows antioxidant, antibacterial, antifungal and antihuman tumor cell lines properties. Food Chem Toxicol 62: 91-98, 2013.

29. Rao YK, Fang SH, Wu WS and Tzeng YM: Constituents isolated from Cordyceps militaris suppress enhanced inflammatory mediator's production and human cancer cell proliferation. J Ethnopharmacol 131: 363-367, 2010.

30. Jing Y, Cui X, Chen Z, Huang L, Song L, Liu T, Lv W and Yu R: Elucidation and biological activities of a new polysaccharide from cultured Cordyceps militaris. Carbohydr Polym 102: 288-296, 2014

31. Wong JH, Wang $\mathrm{H}$ and $\mathrm{Ng} \mathrm{TB}$ : A haemagglutinin from the medicinal fungus Cordyceps militaris. Biosci Rep 29: 321-327, 2009.

32. Nourazarian SM, Nourazarian A, Majidinia M and Roshaniasl E: Effect of root extracts of medicinal herb Glycyrrhiza glabra on HSP90 gene rxpression and apoptosis in the HT-29 colon cancer cell line. Asian Pac J Cancer Prev 16: 8563-8566, 2015.

33. Hu B, An HM, Wang SS, Chen JJ and Xu L: Preventive and therapeutic effects of Chinese herbal compounds against hepatocellular carcinoma. Molecules 21: 142, 2016.

34. Fulda S and Debatin KM: Extrinsic versus intrinsic apoptosis pathways in anticancer chemotherapy. Oncogene 25: 4798-4811, 2006.

35. Zhang Y, Xie RF, Xiao QG, Li R, Shen XL and Zhu XG: Hedyotis diffusa Willd extract inhibits the growth of human glioblastoma cells by inducing mitochondrial apoptosis via AKT/ERK pathways. J Ethnopharmaco 158: 404-411, 2014.

36. Hengartner MO: The biochemistry of apoptosis. Nature 407: 770-776, 2000.

37. Galluzzi L, Vitale I, Kepp O, Séror C, Hangen E, Perfettini JL, Modjtahedi N and Kroemer G: Methods to dissect mitochondrial membrane permeabilization in the course of apoptosis. Methods Enzymol 442: 355-374, 2008.

38. Hisatomi T, Ishibashi T, Miller JW and Kroemer G: Pharmacological inhibition of mitochondrial membrane permeabilization for neuroprotection. Exp Neurol 218: 347-352, 2009.

39. Schug ZT, Gonzalvez F, Houtkooper RH, Vaz FM and Gottlieb E: BID is cleaved by caspase- 8 within a native complex on the mitochondrial membrane. Cell Death Differ 18: 538-548, 2011.

40. Hyun HB, Lee WS, Go SI, Nagappan A, Park C, Han MH, Hong SH, Kim G, Kim GY, Cheong J, et al: The flavonoid morin from Moraceae induces apoptosis by modulation of Bcl-2 family members and Fas receptor in HCT 116 cells. Int J Oncol 46: 2670-2678, 2015

41. Lee JW, Park C, Han MH, Hong SH, Lee TK, Lee SH, Kim GY and Choi YH: Induction of human leukemia U937 cell apoptosis by an ethanol extract of Dendropanax morbifera Lev. Through the caspase-dependent pathway. Oncol Rep 30: 1231-1238, 2013.

42. Lee KH, Feig C, Tchikov V, Schickel R, Hallas C, Schütze S, Peter ME and Chan AC: The role of receptor internalization in CD95 signaling. EMBO J 25: 1009-1023, 2006.

43. Liu XF, Jiang H, Zhang CS, Yu SP, Wang ZQ and Su HL: Targeted drug regulation on methylation of p53-BAX mitochondrial apoptosis pathway affects the growth of cholangiocarcinoma cells. J Int Med Res 40: 67-75, 2012.

44. Kroemer G, Galluzzi L and Brenner C: Mitochondrial membrane permeabilization in cell death. Physiol Rev 87: 99-163, 2007.

45. Bao Q and Shi Y: Apoptosome: A platform for the activation of initiator caspases. Cell Death Differ 14: 56-65, 2007.

46. Porter AG and Jänicke RU: Emerging roles of caspase-3 in apoptosis. Cell Death Differ 6: 99-104, 1999.

47. Visagie M, Theron A, Mqoco T, Vieira W, Prudent R, Martinez A, Lafanechère L and Joubert A: Sulphamoylated 2-methoxyestradiol analogues induce apoptosis in adenocarcinoma cell lines. PLoS One 8: e71935, 2013.

48. Tor YS, Yazan LS, Foo JB, Armania N, Cheah YK, Abdullah R, Imam MU, Ismail N and Ismail M: Induction of apoptosis through oxidative stress-related pathways in MCF-7, human breast cancer cells, by ethyl acetate extract of Dillenia suffruticosa. BMC Complement Altern Med 14: 55, 2014

49. Woo M, Hakem R, Soengas MS, Duncan GS, Shahinian A, Kägi D, Hakem A, McCurrach M, Khoo W, Kaufman SA, et al: Essential contribution of caspase 3/CPP32 to apoptosis and its associated nuclear changes. Genes Dev 12: 806-819, 1998. 
50. Liu J, Wu Y, Wang B, Yuan X and Fang B: High levels of glucose induced the caspase-3/PARP signaling pathway, leading to apoptosis in human periodontal ligament fibroblasts. Cell Biochem Biophys 66: 229-237, 2013.

51. Benjamin RC and Gill DM: Poly (ADP-ribose) synthesis in vitro programmed by damaged DNA. A comparison of DNA molecules containing different types of strand breaks. J Biol Chem 255: 10502-10508, 1980.
52. Wang H, Shimoji M, Yu SW, Dawson TM and Dawson VL: Apoptosis inducing factor and PARP-mediated injury in the MPTP mouse model of Parkinson's disease. Ann N Y Acad Sci 991: 132-139, 2003.

53. Shi Y, Zhou F, Jiang F, Lu H, Wang J and Cheng C: PARP inhibitor reduces proliferation and increases apoptosis in breast cancer cells. Chin J Cancer Res 26: 142-147, 2014. 